\title{
KEPUASAN PELANGGAN DITINJAU DARI HARGA, LOKASI DAN INOVASI PRODUK PADA MOTOR YAMAHA
}

\author{
(Studi Pada Dealer Motor Yamaha Nusukan Surakarta) \\ Andre Pradana, Sarsono, Sudarwati \\ Fakultas Ekonomi Universitas Islam Batik Surakarta \\ Email : pradanacupet23@gmail.com
}

\begin{abstract}
Abstrak : Penelitian ini bertujuan untuk mengetahui: (1) Untuk mengetahui pengaruh secara simultan harga, lokasi dan inovasi produk terhadap kepuasan pelanggan pada delaer motor Yamaha nusukan (2) Untuk mengetahui pengaruh harga terhadap kepuasan pelanggan didealer motor yamaha nusukan (3) Untuk mengetahui pengaruh lokasi terhadap kepuasan pelanggan didealer motor yamaha nusukan (4) Untuk mengetahui pengaruh inovasi produk terhadap kepuasan pelanggan didealer motor yamaha nusukan. Penelitian ini merupakan penelitian kuantitatif. Populasi pada penelitian ini adalah seluruh pelanggan yang pernah membeli 2 kali produk/jasa di dealer motor Yamaha nusukan surakarta. Teknik pengambilan sampel menggunakan purposive sampling dengan jumlah sampel sebanyak 100 orang. Teknik pengumpulan data menggunakan kuesioner yang telah di uji validitas dan reabilitasnya. Teknik analisis data yang digunakan adalah regresi linier berganda. Hasil penelitian menunjukkan bahwa harga, lokasi dan inovasi produk berpengaruh secara simultan terhadap kepuasan pelanggan pada delaer motor Yamaha nusukan, harga berpengaruh terhadap kepuasan pelanggan didealer motor yamaha nusukan, lokasi berpengaruh terhadap kepuasan pelanggan didealer motor yamaha nusukan, inovasi produk berpengaruh terhadap kepuasan pelanggan didealer motor yamaha nusukan.
\end{abstract}

Kata Kunci: Harga, Lokasi, Inovasi Produk dan Kepuasan.

Abstract : The exploration goals toward discovery available: (1) to know the simultaneous influence of prices, location and product innovation to customer satisfaction on Yamaha motor Delaer Nusukan (2) to know the bearing of amount to buyer approval dealer Yamaha Nusukan (3) to know the bearing of the location on buyer approval dealers dealer Yamaha Nusukan (4) to know the effect of produce innovations to buyer approval dealers Yamaha Nusukan. This study is a quantitative study. The people in this exploration is all clienteles who have ever bought 2 times the product/package in motorcycle dealers in Yamaha Nusukan Surakarta. Sampling techniques use purposive specimen through a example amount of 100 individuals. The data collection techniques use questionnaires that have been tested for their validity and reliability. The data analysis technique used is multiple linear regression. Fallouts presented that the price, location and product innovation are simultaneously influential to customer satisfaction on Yamaha motor Delaer Nusukan, price affects the satisfaction of customers dealer Yamaha Nusukan, the location affects the satisfaction of customers dealers dealer Yamaha Nusukan, product innovations affect the satisfaction of customers dealers dealer Yamaha Nusukan.

Keywords: price, location, product innovation and satisfaction. 


\section{PENDAHULUAN}

Perkembangan perdagangan pada era globalisasi ini membuat persainganayang semakinaketat dalamamemasarkan produkadan jasa, asehingga setiap perusahaan dituntut untuk selalu berusaha keras dalam berinovasi terhadap produk maupun jasanya agar mampu bertahan dari persaingan dan mampu menarik perhatian dari calon konsumen akan produk yang ia tawarkan. Hal yang perlu diperhatikan sebelum merancang inovasi, seseorang harus jelas terlebih dahulu segmentasi dan target mana yang akan disasar. Selain tiap perusahaan dituntut untuk membuat perubahan perubahan yang dapat meningkatkan produknya, perusahaan juga diharapkan dapat memasarkan produk atau jasanya kepada calon konsumen, dengan tujuan agar produk tersebut dapat dikenal oleh masyarakat (Avetoe et al. 2015).

Perkembangan dunia saat ini berjalan dengan pesat, sehingga membuat suatu persaingan yang semakin ketat, hal ini menjadikan perusahaan untuk meningkatkan volume penjualan terhadap produk yang dikeluarkan. Produsen dituntut untuk lebih peka, kritis dan reaktif terhadap perubahan yang ada, baik politik, sosial budaya, dan ekonomi. Syarat yang harus dipenuhi oleh suatu perusahaan agar dapat mencapai sukses dalam persaingan adalah berusah mencapai tujuan untuk menciptakan dan mempertahankan pelanggan. Untuk mencapai tujuan tersebut, maka setiap perusahaan harus berupaya menghasilkan dan menyampaikan barang dan jasa yang diinginkan konsumen dengan harga yang pantas. Perusahaan harus mampu memahami kelangsungan hidup perusahaan tersebut. Perusahaaan sangat tergantung pada perilaku konsumennya, karena perusahaan adalah organisasi yang berusaha memenuhi kebutuhan dan keinginan para konsumen (Tjiptono, 2005). Perusahaan harus bekerja keras membuat kebijakan- kebijakan strategis baru dalam menjual produk dan jasa mereka dalam kaitannya menghadapi persaingan yang ketat dengan competitor yang dapat memberikan peningkatan volume penjualan yang lebih besar terhadap produk yang dijual. Tumbuhnya perusahaan perusahaan baru menjadikan banyak pilihan bagi pelanggan untuk dapat memilih produk yang sesuai dengan apa yang menjadi harapannya. Konsekuensi dari perubahan tersebut adalah pelanggan menjadi lebih cermat dan pintar dalam menghadapi setiap produk yang diluncurkan di pasar. Masyarakat kini mulai berpikir selektif dan smart dalam memilih suatu produk, sehingga mereka akan mendapatkan kegunaan atau manfaat yang mereka cari dari sebuah produk. Konsumen pada saat ini tidak ragu untuk mengeluarkan biaya lebih untuk mendapatkan produk yang berkualitas. Ketatnya persaingan akan memposisikan pemasar untuk selalu mengembangkan dan merebut market share.

Perusahaan dalam menjalankan aktivitas bisnis atau kegiatan usaha, umumnya yang harus diperhatikan perusahaan adalah orientasi pelanggan atau costumer orientation, yaitu menyangkut apa yang harus dipuaskan perusahaan terhadap pelanggannya. Perusahaan harus lebih memperhatikan aspek tersebut tentunya tujuan yang ingin dicapai perusahaan akan terwujud. Dunia usaha atau bisnis, khususnya yang bergerak dibidang jasa, satisfaction/kepuasan merupakan factor yang dominan dan menentukan dalam mempertahankan maupun menumbuhkembangkan perusahaan. Perusahaan yang gagal memuaskan pelanggannya akan menghadapi masalah yang lebih komplek, dikarenakan dampak bad word of mouth. Umumnya pelanggan yang tidak puas akan menyampaikan pengalaman buruknya kepada 11 orang lain (Kotler, 2001). Setiap orang dari 11 orang ini meneruskan informasi tersebut kepada orang yang lain lagi, maka berita buruk ini bisa berkembang secara luas. Perusahaan akan mendapat kerugian dari kegagalan memuaskan harapan pelanggan. Produsen jasa wajib merencanakan, mengorganisasikan, mengimplementasikan dan mengendalikan sistem kualitas sedemikian rupa sehingga pelayanan dapat memuaskan para pelanggannya. Perusahaan harus memperhatikan hal-hal yang dianggap penting oleh para konsumen maupun pelanggannya agar mereka puas sesuai dengan harapannya. 
Dari sekian banyak bisnis yang berkembang dalam bidang jasa salah satunya adalah Dealer Motor Yamaha Nusukan merupakan bengkel resmi Yamaha yang berdiri sejak tahun 2005. Dalam usaha menjalankan bisnisnya Dealer Motor sebagai perusahaan penyalur sepeda motor terbesar dan terbaik di Indonesia dalam penjualan (sales), perawatan (service), dan suku cadang (spare part) Sepeda Motor Yamaha. Oleh karena itu Dealer Motor Yamaha Nusukan dalam meningkatkan kepuasan konsumen berusaha memberikan kualitas pelayanan yang optimal kepada pelanggannya.

Dari latar belakang diatas maka penulis mengangkat judul "Kepuasan Pelanggan Ditinjau Dari Harga, Lokasi Dan Inovasi Produk Pada Motor Yamaha (Studi Kasus Pada Dealer Motor Yamaha Nusukan Surakarta)".

\section{LANDASAN TEORI}

Menurut Philip Kotler dan KL Keller (2007) mengemukakan bahwa kepuasan dapat diartikan sebagai "upaya pemenuhan sesuatu" atau "membuat sesuatu memadai". Kepuasan (satisfaction) adalah perasaan senang atau kecewa seorang yang muncul setelah membandingkan kinerja (hasil) produk yang dipikirkan terhadap kinerja (atau hasil) yang diharapkan. Menurut kamus besar bahasa Indonesia, kepuasan mempunyai kata dasar "puas" yang berarti merasa senang, lega, karena sudah terpenuhi apa yang diinginkan, sedangkan kata kepuasan itu sendiri memiliki arti yang bersifat puas (kesenangan) maknanya rasa puas seseorang akan timbul ketika suatu hasratnya terpenuhi.

Harga adalah uang yang ditentukan oleh perusahaan sebagai imbalan barang atau jasa yang diperdagangkan. Harga adalah sejumlah uang yang dibutuhkan untuk mendapatkan sejumlah kombinasi dari barang peserta pelayanannya" (Basu Swastha, 2002: 137).

"Keputusan bauran harga berkenaan dengan kebijakan strategis dan taktis, seperti tingkat harga, struktur diskon, syarat pembayaran dan tingkat diskriminasi harga diantara berbagai kelompok pelanggan" (Fandi Tjiptono, 2005: 31). Menurut Bob Sabran (2011:67), harga adalah suatu elemen bauran pemasaran yang menghasilkan pendapatan, elemen lain menghasilkan biaya. Harga merupakan elemen termudah dalam program pemasaran untuk disesuaikan, fitur produk, saluran, dan bahkan komunikasi membutuhkan banyak waktu.

Lokasi adalah keputusan yang dibuat perusahaan berkaitan dengan di mana operasi dan stafnya akan ditempatkan. Menurut Fandy Tjiptono (2005: 42), indikator lokasi yang harus dipertimbangkan adalah sebagai berikut: akses, visibilitas, tempat parkir yang luas, aman, nyaman dan lingkungan yang mendukung.

Menurut Zeithaml (1988), "kualitas dapat didefinisikan secara luas sebagai superioritas atau keunggulan". Di sini, Kotler dan Armstrong (2008) menggambarkan bahwa "produk adalah sesuatu yang dapat ditawarkan ke pasar untuk perhatian, akuisisi, penggunaan, atau konsumsi yang mungkin memenuhi keinginan atau kebutuhan ", sementara Ehsani (2015), mengatakan bahwa " inovasi produk adalah persepsi pelanggan tentang kualitas atau superioritas keseluruhan produk atau layanan, sehubungan dengan tujuan yang dimaksudkan, relative terhadap alternatif". Kotler dan Amstrong (2008) mengasumsikan bahwa inovasi produk adalah adalah karakteristik dari suatu produk atau layanan yang menanggung kemampuannya untuk memenuhi kebutuhan pelanggan yang dinyatakan atau tersirat".

\section{METODE PENELITIAN}

Metode Penelitian ini menggunakan pendekatan kuantitatif deskriptif. Penulis memilih menggunakan metode ini untuk mengetahui besaran pengaruh serta signifikansi antara harga, lokasi dan inovasi produk terhadap kepuasan pelangan. Penelitian ini di lakukan di 
Dealer Motor Yamaha Nusukan di Surakarta. Populasi dalam penelitian ini adalah pelanggan pada motor Yamaha nusukan dengan sampel sebanyak 100 respoden. Teknik sampling yang digunakan dalam penelitian ini adalah purposive sampling.

Data primer pada penelitian ini adalah data yang diperoleh secara langsung dari responden dengan menggunakan kuesioner, wawancara dan pengamatan yang diberikan secara langsung kepada responden untuk memperoleh informasi tentang faktor-faktor yang mempengaruhi kepuasan pelanggan. Data sekunder yang penulis gunakan dalam penelitiuan ini berupa data yang diperoleh dari sumber sumber lain yang berhubungan dengan penelitian.

Teknik pengumpulan data dalam penelitian ini dilakukan dengan 4 metode, yaitu: observasi, dokumentasi dan kuisioner. Uji instrument dalam penelitian ini menggunakan 2 metode, yaitu dengan uji validitas dan uji reliabilitas. Penelitian ini dalam analisis data mengunakan metode uji asumsi klasik yang terdiri dari uji normalitas, uji multikolinearitas, uji autokorelasi dan heterokedastiisitas sedangkan untuk uji hipotesa terdiri dari regresi linier berganda, vji F dan vji T.

\section{HASIL DAN PEMBAHASAN}

A. Gambaran Perusahaan

Sejak awal Dealer Yamaha Nusukan merupakan perusahaan yang bergerak di bidang distribusi sepeda motor.Adanya kesepakatan dari ATPM Yamaha dan Dealer Yamaha Nusukan, dengan resmi Dealer Yamaha Nusukan ditunjuk sebagai dealer resmi Yamaha. Seiring berjalannya waktv, yang awalnya Dealer Yamaha Nusukan hanya membuka 3 showroom, kini telah berkembang dengan begitu pesatnya sehingga saat ini telah mempunyai 32 jaringan penjualan, pelayanan purna jual dan suku cadang yang tersebar di berbagai area di Solo, meliputi Eks Kariisidenan Surakarta. Pada usianya yang relatif masih sangat muda, Dealer Yamaha Nusukan telah ikut menyumbangkaan penjualan produk dalam mendongkrak pasar dalam negeri untuk produk produk sepeda motor Yamaha di Jawa Tengah. Dengan omzet penjualan yang terus meningkat dari waktu ke waktu,saat ini Dealer Yamaha Nusukan telah menjadi salah satu perusahaan distribusi sepeda motor Yamaha yang terbesar dan terpercaya di Surakarta. Filosofi dari Yamaha Dealer Yamaha Nusukan yaitu, bekerja adalah ibadah,kepuasan pelanggan adalah komitmen,kerja tim adalah kekuatan,kerja keras adalah kebiasaan,dan perubahan serta perbaikan adalah kunci sukses dealer tersebut.

B. Deskripsi Responden

Penelitian dilakukan pada bulan Januari 2020 pada pelanggan dealer motor yamaha yang berada di Nusukan Surakarta. Berdasarkan kelengkapan data yang diperoleh, di dapatkan sampel sebanyak 100 sampel. Deskripsi responden dapat disajikan berdasarkan jenis kelamin, usia dan status pegawai.

Berdasarkan hasil kuisioner menunjukan responden yang menjadi pelanggan di dealer motor Yamaha nusukan didominasi oleh laki-laki sebanyak 61 orang dibandingkan dengan perempuan hanya 29 orang. Hal ini mungkin disebabkan laki-laki lebih suka atau lebih perhatian terhadap kendaraan pribadinya.

Berdasarkan hasil kuisioner menunjukan responden yang menjadi pelanngan di dealer motor Yamaha nusukan didominasi oleh umur 31 - 40 tahun sebanyak 41 orang dan selanjutnya umur 25 - 30 tahun sebanyak 29, umur $41-50$ tahun sebanyak 23 orang, umur < 25 tahun sebanyak 21 orang dan umur $>50$ tahun sebanyak 10 orang. Hal ini disebabkan orang 
pada umur 31-40 tahun sudah memiliki pekerjaan tetap sehingga mendapatkan pendapatan tiap bulannya untuk membeli kendaraan pribadinya.

Berdasarkan hasil kuisioner menunjukan responden yang menjadi pelanngan di dealer motor Yamaha nusukan didominasi oleh wiraswastawan sebanyak 35 orang dan selanjutnya pelajar/mahasiswa sebanyak 27, pegawai swasta sebanyak 23 orang dan PNS sebanyak 15 orang. Hal ini mungkin disebabkan karena wiraswastawan lebih memiliki banyak waktu luang sehingga dapat melakukan prawatan kepada kendaraan pribadinya secara rutin.

C. Hasil Analisis

1) Analisa Data

a. Statistik Deskriptif

Statistik deskriptif dalam penelitian ini dari variabel penelitian merupakan penjelasan data disertai dengan nilai minimum, nilai maksimum, mean dan standar deviasi. Descriptive statistics data penelitian yang terdiri dari harga, lokasi dan inovasi produk.

\begin{tabular}{|l|r|r|r|r|r|}
\hline & \multicolumn{7}{|c|}{ Descriptive Statistics } & & \\
\hline & N & Minimum & Maximum & Mean & Std. Deviation \\
\hline Harga & 100 & 2.8 & 5 & 4.03 & .5441 \\
\hline Lokasi & 100 & 2.8 & 5 & 4.11 & .5608 \\
\hline Inovasi Produk & 100 & 2.8 & 5 & 4.22 & .4759 \\
\hline Kepuasan Pelanggan & 100 & 2.6 & 5 & 4.17 & .6023 \\
\hline Valid N (listwise) & 100 & & & & \\
\hline
\end{tabular}

b. Uji Asumsi Klasik

Uji asumsi klasik dalam penelitian ini dilakukan untuk memenuhi asumsi normalitas, multikolinearitas, autokorelasi dan heteroskedastisitas. Hasil asumsi klasik adalah sebagai berikut: 
1) Uji Normalitas

\begin{tabular}{|c|c|c|}
\hline \multicolumn{3}{|c|}{ One-Sample Kolmogorov-Smirnov Test } \\
\hline & & $\begin{array}{c}\text { Unstandardized } \\
\text { Residual }\end{array}$ \\
\hline \multicolumn{2}{|l|}{$\mathrm{N}$} & 100 \\
\hline \multirow[t]{2}{*}{ Normal Parameters } & Mean & .0000000 \\
\hline & Std. Deviation & .41238905 \\
\hline \multirow[t]{3}{*}{ Most Extreme Differences } & Absolute & .068 \\
\hline & Positive & .051 \\
\hline & Negative & -.068 \\
\hline \multicolumn{2}{|l|}{ Test Statistic } & .068 \\
\hline \multicolumn{2}{|l|}{ Asymp. Sig. (2-tailed) } & $200 \stackrel{\mathrm{cod}}{=}$ \\
\hline
\end{tabular}

Uji normalitas variabel independen dan variabel terdistribusikan secara normal atau tidak. Untuk menguji apakah data penelitian ini terdistribusi normal atau tidak dapat dideteksi melalui uji one sample Kolmogorov-Sminov.

Dari hasil pengujian terlihat nilai Asymp. Sig. (2-tailed) pada tabel diatas sebesar 0,200 dan nilainya lebih besar dari $\alpha=0,05$. Hal ini berarti data residual terdistribusi normal.

2) Uji Multikolinearitas

\begin{tabular}{|c|c|c|c|c|c|c|c|c|}
\hline \multicolumn{9}{|c|}{ Coefficients $^{a}$} \\
\hline \multirow{2}{*}{\multicolumn{2}{|c|}{ Model }} & \multicolumn{2}{|c|}{$\begin{array}{l}\text { Unstandardized } \\
\text { Coefficients }\end{array}$} & \multirow{2}{*}{$\begin{array}{l}\text { Standardized } \\
\text { Coefficients } \\
\text { Beta }\end{array}$} & \multirow{3}{*}{$\begin{array}{c}\mathrm{t} \\
-.108\end{array}$} & \multirow{3}{*}{$\begin{array}{l}\text { Sig. } \\
.915\end{array}$} & \multicolumn{2}{|c|}{$\begin{array}{l}\text { Collinearity } \\
\text { Statistics }\end{array}$} \\
\hline & & B & Std. Error & & & & $\begin{array}{l}\text { Toler } \\
\text { ance }\end{array}$ & VF \\
\hline \multirow[t]{4}{*}{1} & (Constant) & -.046 & .427 & & & & & \\
\hline & Harga & .297 & .102 & .268 & 2.899 & .005 & .571 & 1.751 \\
\hline & Lokasi & .401 & .098 & .374 & 4.084 & .000 & .583 & 1.714 \\
\hline & $\begin{array}{l}\text { Inovasi } \\
\text { Produk }\end{array}$ & .325 & .098 & .256 & 3.309 & .001 & .813 & 1.230 \\
\hline
\end{tabular}

Uji multikolinearitas dilakukan untuk menguji apakah pada model regresi ditemukan adanya korelasi antar variabel independen. Jika terjadi 
korelasi, maka dinamakan terdapat problem Multikolinearitas. Model regresi yang baik seharusnya tidak terjadi korelasi diantara variabel independen.Pengujian ada tidaknya gejala multikolinearitas dilakukan dengan memperhatikan nilai matriks korelasi yang dihasilkan pada saat pengolahan data serta nilai VIF (Variance Inflation Factor) dan Tolerancenya. Nilai darii $\mathrm{VIF}<10$ dan tolerance $>0.1$, menandakan tidak terjadi adanya gejala multikolinearitas.

Hasilperhitungan pada tabel diperoleh nilai VIF masingmasing variabel bebas (harga, lokasi dan inovasi produk) kurang dari 10 dan tolerance yang lebih dari 0,1 , dengan demikian dapat simpulkan bahwa model regresi dalam penelitian ini tidak terjadi gejala multikolinearitas.

3) Uji Autokorelasi

\begin{tabular}{|c|c|c|c|c|c|}
\hline \multicolumn{6}{|c|}{ Model Summary } \\
\hline Model & $\mathrm{R}$ & R Square & $\begin{array}{c}\text { Adjusted R } \\
\text { Square } \\
\end{array}$ & $\begin{array}{l}\text { Std. Error of } \\
\text { the Estimate }\end{array}$ & $\begin{array}{l}\text { Durbin- } \\
\text { Watson }\end{array}$ \\
\hline 1 & $.729^{3}$ & .531 & .517 & .419 & 2.025 \\
\hline
\end{tabular}

Autokorelasi muncul karena observasi yang berurutan sepanjang waktu berkaitan satu sama lainnya. Masalah ini timbul karena residual tidak bebas dari satu observasi ke observasi lainnya. Gejala autokorelasi dideteksi dengan menggunakan uji Durbin Watson (DW) dengan cara nilai DW dibandingkan dengan nilai tabel dengan menggunakan signifikansi $5 \%$.

Hasil perhitungan di atas dapat dijelaskan bahwa DW sebesar 2.025 akan dibandingkan dengan nilai tabel dengan menggunakan nilai signifikansi 5\%, jumlah sampel $100 \quad$ (n) dan jumlah variabel independen $3(\mathrm{k}=3)$, maka di tabel Durbin Watson didapatkan nilai $\mathrm{DU}=1,736$ dan $\mathrm{DL}=1.613$. Nilai $\mathrm{DW} 2.025$ berada diantara batas $4-\mathrm{DU}=2,264$ dan $\mathrm{DU}=1,736$ dapat disimpulkan bahwa tidak terdapat autokorelasi. 
4) Uji Heteroskedastisitas

\begin{tabular}{|c|c|c|c|c|c|c|}
\hline \multicolumn{7}{|c|}{ ANOVA $^{a}$} \\
\hline \multicolumn{2}{|c|}{ Model } & $\begin{array}{l}\text { Sum of } \\
\text { Squares }\end{array}$ & df & $\begin{array}{l}\text { Mean } \\
\text { Square }\end{array}$ & $\mathrm{F}$ & Sig. \\
\hline \multirow[t]{3}{*}{1} & $\begin{array}{l}\text { Regressio } \\
n\end{array}$ & 19.085 & 3 & 6.362 & 36.274 & $.000^{\circ}$ \\
\hline & Residual & 16.836 & 96 & .175 & & \\
\hline & $\begin{array}{l}\text { Total } \\
\text { : }\end{array}$ & 35.922 & 99 & & & \\
\hline \multicolumn{7}{|c|}{ a. Dependent Variable: Kepuasan Pelanggan } \\
\hline
\end{tabular}

Heteroskedastisitas bertujuan untuk menguji apakah dalam model regresi terjadi ketidaksamaan variance dari residual satu pengamatan ke pengamatan yang lain signifikan, maka disebut homoskedastitas dan tidak signifikan disebut heteroskedastisitas. Model regresi yang baik adalah homoskedastisitas atau tidak terjadi heteroskedastisitas.Untuk menguji ada tidaknya heteroskedastisitas didalam penelitian ini menggunakan uji Glejser yaitu dengan cara meregresikan nilai absolute residual terhadap variable independen. Ada tidaknya heteroskedastisitas diketahui dengan melihat probabilitas > 0,05 maka tidak terjadi heteroskedastisitas dan sebaliknya jika niali $\mathrm{P}$ value $<0,05$ maka terjadi heteroskedastisitas.

Berdasarkan tabel diatas dapat kita lihat nilai $\mathrm{P}$ atau Sig menunjukan nilai 0.000 yang berarti bahwa $<0.05$ sehingga dapat dikatakan tidak terdapat heteroskedasititas

2. Uji F

\begin{tabular}{|c|c|c|c|c|c|c|}
\hline \multicolumn{7}{|c|}{ ANOVA $^{a}$} \\
\hline \multicolumn{2}{|c|}{ Model } & $\begin{array}{l}\text { Sum of } \\
\text { Squares }\end{array}$ & $\mathrm{df}$ & $\begin{array}{c}\text { Mean } \\
\text { Square }\end{array}$ & $\mathrm{F}$ & Sig. \\
\hline \multirow[t]{3}{*}{1} & Regression & 19.085 & 3 & 6.362 & 36.274 & $.000^{\circ}$ \\
\hline & Residual & 16.836 & 96 & .175 & & \\
\hline & Total & 35.922 & 99 & & & \\
\hline \multicolumn{7}{|c|}{ a. Dependent Variable: Kepuasan Pelanggan } \\
\hline \multicolumn{7}{|c|}{ b. Predictors: (Constant), Inovasi Produk, Lokasi, Harga } \\
\hline
\end{tabular}

Dari uji ANOVA atau $\mathrm{F}$ test di dapat nilai $\mathrm{F}$ hitung sebesar 36,274 > F Tabel $=2,38($ df $1=\mathrm{k}=3$ dan $\mathrm{df} 2=\mathrm{n}-\mathrm{k}-1=100-3-1=96, \alpha=0,05)$. Maka dapat disimpulkan bahwa harga, lokasi dan inovasi produk secara simultan berpengaruh terhadap kepuasan pelanggan. 
3. Ujit

\begin{tabular}{|c|c|c|c|c|c|c|}
\hline \multicolumn{7}{|c|}{ Coefficients $^{a}$} \\
\hline & & \multicolumn{2}{|c|}{$\begin{array}{c}\text { Unstandardized } \\
\text { Coefficients }\end{array}$} & \multirow{2}{*}{$\begin{array}{c}\text { Standardized } \\
\text { Coefficients } \\
\text { Beta } \\
\end{array}$} & \multirow[b]{2}{*}{$\mathrm{t}$} & \multirow[b]{2}{*}{ Sig. } \\
\hline \multicolumn{2}{|c|}{ Model } & $\mathrm{B}$ & Std. Error & & & \\
\hline \multirow[t]{4}{*}{1} & (Constant) & -.046 & .427 & & -.108 & .915 \\
\hline & Harga & .297 & .102 & .268 & 2.899 & .005 \\
\hline & Lokasi & .401 & .098 & .374 & 4.084 & .000 \\
\hline & Inovasi Produk & .325 & .098 & .256 & 3.309 & .001 \\
\hline
\end{tabular}

\section{Hipotesis 1 : Harga, lokasi dan kualitas pelayanan berpengaruh secara signfikan terhadap kepuasan pelanggan}

Variabel harga (X1), lokasi (X2) dan inovasi produk (X3) memiliki nilai $\mathrm{F}$ hitung sebesar 36,274 $>\mathrm{F}$ Tabel $=2,38$ dengan signifikansi $0.000<\alpha=0.05$ serta bertanda positif, maka Ho ditolak dan menerima Ha, sehingga hipotesis penelitian yang menyatakan bahwa Harga, lokasi dan kualitas pelayanan berpengaruh secara signfikan terhadap kepuasan pelanggan dealer Dealer Yamaha Nusukan dapat diterima.

Tujuan pengujian ini adalah untuk mengetahui apakah masingmasing variabel independensi mempengaruhi variabel dependen secara signifikan. Untuk pengujian secara individual ini digunakan uji t. Hasil perhitungan statistik pada pengujian secara individual ditunjukkan pada Tabel sebagai berikut: Tujuan pengujian ini adalah untuk mengetahui apakah masing-masing variabel independensi mempengaruhi variabel dependen secara signifikan. Untuk pengujian secara individual ini digunakan uji t. Hasil perhitungan statistik pada pengujian secara individual ditunjukkan pada Tabel sebagai berikut:

\section{Hipotesis 2 : Harga berpengaruh terhadap kepuasan pelanggan}

Dari tabel nilai t-hitung harga (X1) adalah sebesar 2,899 lebih besar dari pada t-tabel yaitu 2,004 dan nilai probabilitas lebih kecil dari 0,05 yaitu sebesar 0,005 Hal ini menunjukkan bahwa variabel harga (X1) berpengaruh positif dan signifikan terhadap kepuasan pelanggan. Dengan demikian, hipotesis pertama dalam penelitian ini diterima.

\section{Hipotesis 3 : Lokasi berpengaruh terhadap kepuasan pelanggan}

Dari tabel nilai t-hitung lokasi (X2) adalah sebesar 4,084 lebih besar dari pada t-tabel yaitu 2,004 dan nilai probabilitas lebih kecil dari 0,05 yaitu sebesar 0,000. Hal ini menunjukkan bahwa variabel lokasi (X2) berpengaruh positif dan signifikan terhadap kepuasan pelanggan. Dengan demikian, hipotesis kedua dalam penelitian ini diterima.

\section{Hipotesis 4 : inovasi produk berpengaruh terhadap kepuasan pelanggan}

Dari tabel nilai t-hitung inovasi produk (X3) adalah sebesar 3,309 lebih besar dari pada t-tabel yaitu 2,004 dan nilai probabilitas lebih kecil 
dari 0,05 yaitu sebesar 0,001. Hal ini menunjukkan bahwa variabel lokasi (X3) berpengaruh positif dan signifikan terhadap kepuasan pelanggan. Dengan demikian, hipotesis ketiga dalam penelitian ini diterima.

4. Analisa Regresi

Analisis regresi adalah studi mengenai variabel dependen dengan satu atau lebih variabel independen, dengan tujuan untuk mengestimasi dan atau memprediksi rata-rata populasi atau nilai rata-rata variabel dependen berdasarkan nilai variabel independen yang diketahui. Dalam analisis regresi, selain mengukur kekuatan hubungan antara dua variabel atau lebih, juga menunjukkan arah hubungan antara variabel dependen dengan variabel independen.

Dari tabel diatas dapat dituliskan dalam persamaan regresi sebagai berikut :

Keterangan :

$$
Y=-0,046+0,297 X_{1}+0,401 X_{2}+0,325 X_{3}
$$

$\mathrm{Y}=$ Kepuasan Pelanggan

$\mathrm{X} 1$ = Harga

$\mathrm{X} 2=$ Lokasi

$\mathrm{X} 3$ = Inovasi Produk

Dari hasil persamaan regresi berganda tersebut masing-masing variabel dapat diinterpretasikan hubungannya dengan tingkat kemandirian sebagai berikut:

a) Konstanta sebesar -0,046 bernilai negatif, artinya jika variabel harga, lokasi dan inovasi produk dianggap tidak ada atau sama dengan 0 maka nilai kemandirian akan turun sebesar $-0,001$

b) Koefisien variabel harga memiliki nilai koefisien sebesar 0,297 mengandung arti bahwa nilai koefisien regresi variabel lainnya tetap, maka pajak daerah mengalami kenaikan sebesar 0,297.

c) Koefisien variabel lokasi memiliki nilai koefisien sebesar 0,401 dengan arah positif hal ini mengandung arti bahwa nilai koefisien regresi variabel lainnya tetap maka retribusi daerah mengalami kenaikan sebesar 0,401.

d) Koefisien variabel inovasi produk adalah sebesar 0,325 dengan arah positif yang berarti bahwa nilai koefisien regresi variabel lainnya tetap, maka dana bagi hasil mengalami kenaikan sebesar 0,325.

\section{KESIMPULAN DAN SARAN}

Kesimpulan dalam penelitian ini adalah variabel harga, lokasi dan inovasi produk memiliki pengaruh yang positif dan signifikan terhadap kepuasan pelanggan secara simultan. Variabel harga memiliki pengaruh yang positif dan signifikan terhadap kepuasan pelanggan di dealer motor yamaha nusukan. Variabel lokasi memiliki pengaruh yang positif dan signifikan terhadap kepuasan pelanggan di dealer motor yamaha nusukan. Variabel inovasi produk memiliki pengaruh yang positif dan signifikan terhadap kepuasan pelanggan di dealer motor yamaha nusukan

Saran pada penelitian ini adalah diharapakan untuk melakukan penelitian lebih lanjut dan mendalam terkait dengan pengaruh inovasi produk, lokasi usaha dan harga terhadap kepuasan pelanggan dengan metode penelitian yang sama dan perusahaan yang 
berbeda guna keberlakuan temuan ini secara lebih luas. Selain itu, penelitian ini perlu dikembangkan dengan mengkaji aspek-aspek lain yang mempengaruhi kepuasan pelanggan.

\section{DAFTAR PUSTAKA}

Avetoe, H. dan Lamidi. 2015. Pengaruh Harga, Kualitas Pelayanan Dan Lokasi Terhadap Keputusan Pembelian Konsumen. Jurnal Ekonomi dan Kewirausahaan Vol. 15 No. 3 : $367-373$.

Basu Swastha, 2002, Manajemen Pemasaran, Liberty, Yogyakarta.

Ehsani, Z and Ehsani, M. H., 2015. Effect of Quality and Price on Customer Satisfaction and Commitment in Iran Auto Industry. International Journal of Service Sciences, Management and Engineering. No.1.Vol 5. pp.5256.

Fandy Tjiptono dan Gregorius Chandra, 2005, Service, Quality dan Satisfaction, Andi Offset, Yogyakarta.

Kotler, Philip dan Keller, KL. Manajemen Pemasaran: Edisi Bahasa Indonesia, Jakarta: PT Indeks, 2007.

Kotler. 2001. Manajemen Pemasaran. Edisi Ketiga Belas. Jilid Dua. Jakarta : Erlangga.

Tjiptono, Chandra. 2005. Perilaku Konsumen dan Komunikasi Pemasaran. Edisi Kesatu.PT.Remaja Rosdakarya.Bandung.

Zeithaml, V.A.1988. Consumer Perceptions of Price, Quality, and Value: A Means-End Model and Synthesis of Evidence. Journal of Marketing Vol.52. pp.2-22. 